\title{
The Obstacles Faced by The National Agency of Drug and Food Control (NA-DFC) of Pekanbaru in Performing the Responsibilities for The Distribution of School Children Food and Snacks (PJAS) Containing Hazardous Substances in Pekanbaru
}

\author{
Ahmad Fuadi ${ }^{*}$, Rosyidi Hamzah ${ }^{2}$, Admiral $^{3}$, Fadhel Arjuna Adinda ${ }^{4}$ \\ Pascasarjana Ilmu Hukum, Universitas Islam Riau,113, Jalan. Kaharuddin Nasution, Pekanbaru, Riau-28284, \\ Indonesia \\ *rosyidihamzah@law.uir.ac.id
}

\begin{abstract}
The high number of business practitioners selling food and snacks that do not comply with the standards established in the laws and regulations at the elementary school areas in Pekanbaru city should be a special concern for authorized officers. Food and snacks containing food additives will be dangerous for people's health if consumed by people. The practice of selling food and snacks containing hazardous substances is not identified directly by the consumers since the form and the taste of the food and snacks are fantastic, and they are sold at cheap price and they do not have direct effects but it can harm the people after some times. The business practitioners mostly sell these kinds of food and snacks around the elementary schools in Pekanbaru city. The target of the business practitioners is school-age children that, based on their age, still do not have critical thinking against food and snacks they buy. The elementary school children, as kids, when purchasing snacks, only look at the form and the taste of the food and snacks without considering the substances contained in the food and snacks. From a study that had been conducted, the obstacle faced by the National Agency of Drug and Food Control (NA-DFC) of Pekanbaru in monitoring the business practitioners who sold food and snacks to children at the elementary school areas in Pekanbaru was that the authority for distributing Food additives was held by the Department of Trade and Industry. This made the National Agency of Drug and Food Control (NA-DFC) was unable to control which one has the rights; the business practitioners secretly used hazardous food additives for snacks they produced. Also, the internal obstacle faced by the NA-DFC was an insufficient number of supervisors. The NA-DFC of Pekanbaru only has 40 supervisors while the NA-DFC work area in Pekanbaru comprises the whole Riau province with 12 regencies and cities.
\end{abstract}

Keywords: Obstacles, Selling Food, Containing Food Additives

\section{INTRODUCTION}

Health is a gift from God and an important thing for humans. When people are sick, it will strongly damage them since they cannot do their activities, such as working, going to school, and the like. Hence, they often spend much money to get the best medical treatment from doctors[1]. Health is one of the human primary needs besides clothes, food, and a house. Without being healthy, people's life becomes meaningless because when we are sick, people cannot do their daily activities well. Therefore, a healthy body should be supported with nutritious food that is beneficial for our health. Considering the body's needs, adequate nutrition intake is required for keeping our body fit and healthy[2].

To actualize the things stated above, the government is trying to manage and provide the people with food. One of the efforts of providing food for the people is by supplying food with high quality yet affordable. High-quality food is food that fulfills the criteria, such as safe, nutritious, and having a high quality. The effort of supplying food for the people makes the business practitioners produce several kinds of food. The food they offer was the food that fulfills the primary, secondary, and tertiary needs[3]. 
The production of those kinds of food is done by the business practitioners to fulfill the consumer needs and attract the consumers' interest to consume the products they make. Several things done by the business practitioners are using attractive packaging, the food product price they offer is affordable for consumers, and the vital point is that using a certain method to offer or promote their food products[4]. The food product packaging used by the business practitioners is not only functioned as packaging, but it also maintains the product safety to prevent it from damage and pollutant (Article 16 Law Number 7 of 1996 on Food). The healthy activity done by business practitioners is certainly based on healthy regulation[5]. Another purpose of using packaging is to attract consumers' attention and interest. For example, in selecting the color of the packaging, the business practitioners tend to use gaudy color to be easily identified by the consumers[6].

The thing shown by the business practitioners to the consumers is mentioning the ingredients they use, the expiry date, and the license obtained from the National Agency of Drug and Food Control. By mentioning the ingredients they use, the consumers will know if the product contains preservatives or not. Besides, the consumers also know if the quality of the product they consume fulfills the quality standard established by the government.

To improve consumer trust, especially Moslem consumers, the business practitioners put a Halal label on the packaging of the product they have produced. The business practitioners obtained this Halal label after passing the process of Halal testing in the Indonesian Ulema Council (MUI). Besides packaging, price is one of the key determinants if the product is saleable in the market.

However, in the reality, many business practitioners sell food and snacks that do not meet the standards established by laws and regulations. Food and snacks containing food additives are dangerous for people's health if they are consumed. The practice of selling food and snacks containing these hazardous substances is not directly identified by the consumers since the form and the taste of the food and the snacks are fantastic and sold at cheap price, and they do not have direct effects but it can harm the people after some times.

The business practitioners who sell these kinds of food and snacks are mostly around the elementary schools in Pekanbaru city. The target of the business practitioners is school-age children that, based on their age, still do not have critical thinking against food and snacks they buy. The elementary school children, as kids, when purchasing snacks, only look at the form and the taste of the food and snacks without considering the substances contained in the food and snacks.

To protect people, especially children, in buying school children food and snacks, the government should be present in supervising the distribution of food containing hazardous food additives. It is done through the National Agency of Drug and Food Control (NA-DFC) in Pekanbaru City with its functions and authorities, namely supervising the circulation of drugs and food. However, in the implementation, they faced many obstacles to perform their authorities, for example, the absence of legal basis owned by the NA-DFC. The legal function is to provide clarity against people's status and products amid the community[7].

The Legal Basis of NA-DFC is only in the form of Presidential Decree on Non-Department State Institutions and it has no special laws. The National Agency of Drug and Food Control strongly needs laws since the task of supervising drugs and food is nationally strategic. According to Aristoteles, the existence of distinct laws will lead people to moral values[8].

Besides, the National Agency of Drug and Food Control (NA-DFC) of Pekanbaru also experiences several obstacles in supervising the circulation of drugs and food, especially school children food and snacks sold around the school areas by the business practitioners to consumers. Based on the statement above, the author was interested in discussing this topic entitled the Obstacles faced by the National Agency of Drug and Food Control (NA-DFC) of Pekanbaru in Performing the Responsibilities for the Distribution of School Children Food and Snacks (PJAS) Containing Hazardous Substances in Pekanbaru City.

\section{METHOD}

From its type, this was categorized as observational research conducted using a survey method by performing the investigation directly in the research location using data collection instruments in the form of interview and a questionnaire. Meanwhile, based on the characteristic, this study was an analytical descriptive study aimed at giving a detailed, clear, and systematic illustration of the main research problems. The research object based on the author was the consumer protection for elementary school students against the fast-food they consumed in the form of food or snacks containing hazardous food additives commonly sold in school areas. 
According to the research title, this study was conducted in the National Agency of Drug and Food Control (NA-DFC) of Riau Province and elementary schools. The reason for selecting the title was the author found that these locations were relevant to this study. The population and the respondents of this study were the snack sellers around the elementary schools in Pekanbaru City and the head of the National Agency of Drug and Food Control (NA-DFC) in Pekanbaru City. The instruments for data collection were interviews and a questionnaire.

\section{RESULT}

1. The Obstacles faced by the National Agency of Drug and Food Control (NA-DFC) of Pekanbaru in Performing the Responsibilities for the Distribution of School Children Food and Snacks (PJAS) Containing Hazardous Substances in Pekanbaru City. The consumers should be treated well morally; it is not an ethical demand only but also the absolute requirement to achieve success in a business. Consumer protection should be performed according to clear purposes. Article 3 Law Number 8 of 1999 mentioned that the purposes of consumer protection are as follows:

- Increasing consumer awareness, capability, and independence for self-protection

- Uplifting consumer's dignity and standards by preventing the negative excess of using goods and/ or services;

- Increasing consumer empowerment in selecting, determining, and demanding the rights of consumers

- Creating a consumer protection system containing the legal certainty element and the information openness as well as the access to obtain information

- Developing the business practitioners' awareness of the importance of consumer protection to increase the honesty and responsibility in performing a business

- Improving the quality of goods and/or services to guarantee the sustainability of manufacturing goods and/or services, consumer's health, security, and safety

In performing the tasks and actualizing the vision and missions, the National Agency of Drug and Food Control (NA-DFC) also has the authority. It is appropriate with the Indonesian Presidential Decree Article 69 Number 103 of 2001 on Position, Duties, Functions, Authorities, Organizational Structure, and the work procedure of Non-Department State Institutions. The authorities are as follows:

- Compiling the macro plan in the relevant sector

- Formulating policies in its sector to support macro development

- The establishment of information in the relevant sector

- The establishment of a requirement of using certain additives for food and the establishment of a guideline for supervising the circulation of drugs and food

- Granting a license and supervision of the circulation of drugs and the supervision of pharmaceutical industries

- The establishment of a guideline for the use of conservation, development, and the supervision of medical plants

In the reality, the National Agency of Drug and Food Control (NA-DFC) needs special laws on drugs and food supervision. The Drug and Food Supervisory Agency strongly needs laws since the drugs and food supervision is nationally strategic. The government should issue the policy since it is related to the public interest. The public interest should be the legislator's goal and the public advantages become the foundation of reasoning.

Several obstacles that should be faced by the National Agency of Drug and Food Control (NA-DFC) to protect consumers from snacks containing dangerous food additives. The obstacle faced by the National Agency of Drug and Food Control (NADFC), according to Ms. Veranika Ginting, is that the authority to distribute food additives is held by the Department of Trade and Industry. It makes the National Agency of Drug and Food Control (NA-DFC) cannot control which one has the rights to use it. The National Agency of Drug and Food Control (NA-DFC) finds the hazardous food additives after it has been mixed with the snacks that are ready to be sold.

Hence, stopping the use of hazardous food additives as the mixture for producing snacks is quite difficult to do. It is because the distribution of food additives is the authority of the Department of Trade and Industry. In other words, the National Agency of Drug and Food Control cannot perform preventive actions to avoid the distribution of hazardous food additives. The National Agency of Drug and Food 
Control can only perform repressive actions after the misuse of hazardous food additives.

The second obstacle is that the business practitioners secretly use hazardous food additives as a mixture for the food that is produced. The snacks sold by the sellers and indirectly taken from the producer make the National Agency of Drug and Food Control difficult to investigate the business practitioners who use hazardous food additives.

The third obstacle was from the internal of the National Agency of Drug and Food Control, namely, insufficient number of supervisors. the National Agency of Drug and Food Control of Pekanbaru only has 40 supervisors while the NA-DFC work area in Pekanbaru comprises the whole Riau province with 12 regencies and cities. Even though the NA-DFC has cooperated with the Health Office to conduct a community outreach by providing training on Food and Health to the Officers of Health Office in all regencies/cities in Riau province.

However, the obstacle was that several officers of the Health Office who have received training, after several months, moved to another division or another area. If so, the NA-DFC cannot do anything since conducting training needs a long time due to the budget or cost for conducting the training.

The fourth obstacle was from the consumers. The people or consumers wanted to eat delicious food at an affordable price. The people were also unwilling to report the incident that damaged them. For example, if the food is expired, the consumers will just throw it away. The consumers think that it is cheap and it should not be a problem. The consumers also have poor knowledge since the public awareness to find information is less, even though the NA-DFC often informs the list of food and drugs that are not worth eating.

Ms. Jenny said that she did not know if the food or snacks consumed by her child contained hazardous food additives or not; the important thing was that it was delicious and cheap. Mr. Agus Nurdin admitted that he did not know if the snacks he consumed contained hazardous food additives or not; he also said that he did not care about the effect caused by food additives if it was dangerous or not; the most important for him was that the snacks consumed by his child were cheap and delicious. He thought that the only effect caused by food additives was having a stomachache.

The effort by the BBPOM in protecting the consumers was by conducting community outreach on good manufacturing practices for food production and sanitation to business practitioners who would run a business. Besides, it can be done by conducting a promotion of laws and regulations on consumer protection and community outreach to Family Welfare Empowerment (PKK), Department of Education, teachers, public FIGUREs, youth organization, health professionals (public health center), school children, universities, and the Consumer Protection Foundation (Institute for Consumer Development and Protection/LP2K), receiving and following up the complaints from the people about problematic food and drugs, providing information related to whether the product is worthy to consume or not, including food, pharmacy (including traditional medicine), and cosmetics through both printed media and electronic media, such as newspapers, leaflet, radio, talk shows in TV, and inspecting some elementary schools taken randomly.

TABLE 1. The List of elementary schools with business practitioners selling hazardous snacks

\begin{tabular}{|c|c|c|c|c|}
\hline \multirow{2}{*}{ No } & \multirow{2}{*}{ Elementary School's Name } & \multicolumn{2}{|c|}{ Indicated } & \multirow{2}{*}{ Description } \\
\cline { 3 - 4 } & SDN 21 Pekanbaru & $\sqrt{ }$ & & Noodles (borax) \\
\hline & SDN 151 Pekanbaru & $\sqrt{ }$ & & Crackers (Rhodamin B) \\
\hline & SDN 77 Pekanbaru & $\sqrt{ }$ & & Agar-agar (Rhodamin B) \\
\hline & SDN 193 Pekanbaru & $\sqrt{ }$ & & Doughnut (formalin) \\
\hline & SDN 160 Pekanbaru & $\sqrt{ }$ & & Fried Snacks (Rhodamin B) \\
\hline
\end{tabular}

Source: Processed Data in the Field in 2019

2. A business has several requirements that should be fulfilled and the regulation in the business is created from the agreement where the business is located. In protecting the consumers, the National
Agency of Drug and Food Control refers to Laws Number 23 of 1992 on Health Affairs, Laws Number 7 on Food, Laws Number 8 on Consumer Protection, and Government Regulation Number 
28 of 2004 on the Safety of Food Quality and Nutrition. Besides Laws, in performing the role, the National Agency of Drug and Food Control also has a vision and several missions. The vision of the NA-DFC is to become a reliable institution that is internationally recognized in the sector of drugs and food control for protecting public health. Meanwhile, the missions of the NA-DFC are:

- Protecting public health from the risk of the distribution of therapeutic products, medical devices, traditional medicine, complementary products, and cosmetics that do not fulfill the quality and safety standards and the benefits, as well as the food products that are not worth eating

- Protecting people from the dangers of abusing or misusing the drug products, narcotics, psychotropics, additives, and the risk of using hazardous products and substances

- Developing original Indonesian drugs with the quality, benefits, and safety that are scientifically accounTABLE and they can be used for improving public health

The result found that one of the efforts of the National Agency of Drug and Food Control for consumer protection was by providing education to business practitioners. This education is about good manufacturing practices for food production by fulfilling the health standards that haven been established by the government. Food production is the activity or process of manufacturing, preparing, processing, making, preserving, packaging, repackaging, and/or changing the form of the food.

According to Government Regulation Number 28 of 2004 on the Safety of Food Quality and Nutrition, the good manufacturing practice is the guideline to produce processed food well as referred to Article 3 letter $\mathrm{c}$ that the manufacturing practice concerning on the food safety aspect is by:

- Preventing the food from being polluted by biological and chemical pollutants as well as other materials that can disturb, damage, and dangerous to health

- $\quad$ illing or preventing pathogenic microorganisms from being alive, and decreasing the number of other microorganisms

- Controlling the process, such as selecting the raw materials, the use of food additives, processing, packaging, storing, or the transporting

3. The business practitioners also receive education on sanitation. Food sanitation is the effort to prevent the possibility of decomposers and pathogens from growing and breeding in food, drinks, equipment, and buildings that can damage food and harm people (Article 1 PP No. 28 of 2004). Even though the National Agency of Drug and Food Control of Pekanbaru had provided education on good manufacturing practices for production and sanitation, the snacks business practitioners could not receive the education. It is because the NA-DFC of Pekanbaru only provided education to the business practitioners of medium to large-scale enterprises.

4. From the result of the study, it can be known that education and survey to production sites are done only once when the business practitioner administers the business permit. The judicial review of the production site is only performed when the business practitioner violates the law in running the business or when the NA-DFC finds the hazardous substances contained in both food and pharmaceutical products. The impact of this structural aspect strongly affects people's attitudes and behavior.

5. The practitioners of small-scale snack industries, such as a home industry, do not have a business permit and they do not receive an education from the NA-DFC and the Health Office. The snacks business practitioners who do not have a business permit tend to violate the law. One of the violations is adding banned food additives for snack production. The existence of illegal business makes the snacks business practitioners are free to violate the law. They feel difficult to be tracked since they are not registered in the Health Office and NA-DFC.

6. Based on the result of the interview stated above, it can be known that one of the efforts of NA-DFC in consumer protection is by providing education to business practitioners, consumers, and people. The education performed by the National Agency of Drug and Food Control to business practitioners is about good manufacturing practice for production by fulfilling the health standards that have been established by the government. Another education provided to business practitioners is about the packaging and the distribution of food in the market.

7. Even though the National Agency of Drug and Food Control of Pekanbaru has provided education on good manufacturing practices to business practitioners in Pekanbaru, not all business practitioners received education on good manufacturing practices. This happened because 
the National Agency of Drug and Food Control of Pekanbaru only provided education to business practitioners who would register their business permit to the National Agency of Drug and Food Control, namely medium to large-scale business practitioners.

8. Mawardi said: "I did not register my product, bakso mini (mini meatball), to either the National Agency of Drug and Food Control or the Health Office; the most important thing for me is that my product is sold out and it fits the consumer's taste; besides, I have never gotten any education from any institutions". Meanwhile, Herman admitted that he did not register the drink he sold to either the National Agency of Drug and Food Control or the Health Office; the most important thing is that the price of the cold drink is affordable for the elementary students and it is tasty. He also added that he had never gotten any education from any institutions.

9. Several results of the interview above showed that many business practitioners who did not get any education from either the National Agency of Drug and Food Control or the Health Office just because they did not have a business permit. In the reality, education and development should be given to all traders to make them understand which snack that can be sold and which one that cannot be sold to people.

10. Education given by the National Agency of Drug and Food Control was done when the business practitioners registered their business permits. As long as the validity period has no problems and there is no problem in the business, the National Agency of Drug and Food Control will not give education to the business practitioners. Conducting education needs more time and energy. An education requires many participants to present, a sufficient place, media (visual aids), the right time, and some instructors. Hence, the Na-DFC used another alternative option in consumer protection. The alternative option is by distributing leaflets about the dangers of food additives and the impacts of their consumption. The NA-DFC also informed the food products containing hazardous food additives via both printed media and electronic media. The NA-DFC stated that the distribution of leaflets and information via media is considered more effective.

11. This empowerment effort performed through education and development is very important since it is not a simple matter, namely, expecting the awareness of business practitioners in running their business, while, generally, the economic principle of the business practitioners is getting profit as maximum as possible with minimum business capital; hence, they often commit fraud in running a business.

\section{CONCLUSION}

The obstacles faced by the National Agency of Drug and Food Control in trying to protect the consumers from consuming snacks containing hazardous food additives (BTP) are as follows: The authority in distributing food additives is held by the Department of Trade and Industry. It makes the NA-DFC unable to control whoever has or does not have the right to use food additives; The business practitioner secretly uses hazardous food additives as a mixture of snack production; The internal obstacle faced by the NAD$\mathrm{FC}$ is an insufficient number of supervisors. The NADFC of Pekanbaru only has 40 supervisors, whereas the NAD-FC work area in Pekanbaru comprises of the whole Riau province with 12 regencies and cities; The last obstacle is from the consumers. People or consumers want to eat delicious yet affordable food. People are also unwilling to report if there is an incident that can harm them.

Consequently, the reinforcement against the functions and duties of the National Agency of Drug and Food Control is required for supervising, processing, and giving sanctions to business practitioners who sell school children snacks containing hazardous substances. The coordination between authorized institutions needs to be synchronized in the form of regulations and technical implementation in the reality to prevent the overlapped authority in supervising food and snacks containing hazardous substances. Consistent and continuous legal elucidation related to production, distribution and the consumption of food and snacks to business practitioners and consumers is required. Consequently, the relevant parties understand the rights and the obligations to minimize the misuse of hazardous food additives in food and snacks sold at schools.

\section{REFERENCES}

[1] Sze S M 1969 Physics of Semiconductor Devices (New York: Wiley-Interscience)

[2] Dorman L I 1975 Variations of Galactic Cosmic Rays (Moscow: Moscow State University Press) p 103 
[3] Caplar R and Kulisic P 1973 Proc. Int. Conf. on Nuclear Physics (Munich) vol 1 (Amsterdam: North-Holland/American Elsevier) p 517

[4] Szytula A and Leciejewicz J 1989 Handbook on the Physics and Chemistry of Rare Earths vol 12, ed $\mathrm{K}$ A Gschneidner Jr and L Erwin (Amsterdam: Elsevier) p 133

[5] Kuhn T 1998 Density matrix theory of coherent ultrafast dynamics Theory of Transport Properties of Semiconductor Nanostructures (Electronic Materials vol 4) ed E Schöll (London: Chapman and Hall) chapter 6 pp 173214. 